J. Clin. Chem. Clin. Biochem.

Vol. 25, 1987, pp. 413-418

(C) 1987 Walter de Gruyter \& Co. Berlin - New York

\title{
Cholestasis in Late Metabolic Acidosis of Prematurely Born Infants
}

\author{
By $H$. Senger ${ }^{1}$ ), G. Boehm, K. Beyreiß and W. Braun \\ Department of Pediatrics, Karl-Marx University Leipzig, Leipzig, GDR
}

(Received May 28, 1986/March 16, 1987)

Summary: Serum concentrations of bile acids and tyrosine were determined in 14 premature infants with late metabolic acidosis and in 13 comparable controls without acidosis (protein intake $2 \mathrm{~g} / \mathrm{kg} \cdot \mathrm{d}$ ). At the same time the bile acids and the catalytic activity concentrations of lipase and trypsin were estimated in the duodenal juice. The daily faecal excretion and the percentage of fat eliminated were measured. In 8 patients with late metabolic acidosis the duodenal studies were repeated one week after late metabolic acidosis.

Infants with late metabolic acidosis showed significantly higher concentrations of bile acids and tyrosine in the serum than the controls $(p<0.0005)$. In the duodenal juice the activities of lipase and trypsin and the concentration of bile acids - especially of dihydroxy bile acids - were decreased $(p<0.001)$. The faecal excretion during late metabolic acidosis was significantly increased, with high percentage of fat. Eight days after late metabolic acidosis all duodenal parameters equalled the range of the control group.

The relations between acidosis, cholestasis, and amino acid transport to the liver are discussed.

\section{Introduction}

It is generally accepted that newborns with immature renal function are susceptible to late metabolic acidosis when given a high protein diet. Subsequent to increased loading with casein from cow's milk, elevated concentrations of methionine, tyrösine, phenylalanine, urea, and ammonia were found in the blood $(1,2)$. After a change of nutrition from native mother's milk to a formula with higher protein, we found a significant increase of bile acids and phenylalanine in the serum (3). There is evidence for amino acid-induced cholestasis in premature infants of very low birth weight with increasing protein intake. Bile acids and alpha-amino-nitrogen showed a high correlation (4).

A possible dependence of the uptake of bile acids and amino acids was postulated from in vitro experiments with basolateral membrane vesicles of hepatocytes in adult (5) and suckling (6) rats. Both acids are transported by a $\mathrm{Na}^{+}$-dependent ATPase. The influ-

1) The paper will be part of the thesis of H.Senger ence of acidosis on bile excretion has been studied previously (7). Both $\mathrm{pH}$ and bicarbonate have been suggested as factors responsible for bile acid-independent bile flow $(8,9)$.

\section{Patients and Procedures}

Fourteen premature infants (most of them of low birth weight) suffering from late metabolic acidosis and 13 comparable newborns without late metabolic acidosis were studied.

Table $1 \mathrm{a}+\mathrm{b}$ gives the clinical data as well as $\mathrm{pH}$ and base excess of patients (a) and controls (b). In order to investigate the duodenal contents a gavage tube was placed in the duodenum for about 8 hours. Before and 30, 60, and 120 minutes after a single feeding, $0.1-1.5 \mathrm{ml}$ duodenal contents were aspirated. Sixty minutes after the feeding, $1.5 \mathrm{ml}$ venous blood was withdrawn as well.

In 8 patients the duodenal study was repeated one week after the late metabolic acidosis.

All infants had been fed every 4 hours, a few of them every 2 hours according to Boehm et al. (10). The protein intake of patients was $2.01 \pm 0.38 \mathrm{~g} / \mathrm{kg} \cdot \mathrm{d}$, that of the control group $1.99 \pm 0.40 \mathrm{~g} / \mathrm{kg} \cdot \mathrm{d}$. The acidosis was corrected with $\mathrm{NaHCO}_{3}$. Two to three days after the late metabolic acidosis the acid base parameters as well as the weight gain had reached normal values. 


\section{Methods}

The location of the tube was monitored by the colour, pH, and lipase activity of the aspirated fluid. In some cases the dilution of duodenal juice with gastric content had to be corrected by analysis of polyethylene glycol- 4000 , which had been added in a $1 \%$ concentration to the feed.

The acid base parameters of the blood and the duodenal pH were determined with the acid-base-analyser AME-1 (Radiometer, Copenhagen).

\section{Serum}

In the serum the total bile acids were measured enzymatically by means of a diaphorase nitroblue tetrazolium chloride-coupled reaction (11). Tyrosine was determined fluorimetrically according to Waakles \& Udenfried (12).

\section{Duodenal juice}

The bile acids of the duodenal fluid were separated by means of thin-layer-chromatography and quantified by densitometry (13). The activity of lipase was determined nephelometrically with the Boehringer test kit. Trypsin was determined according to Hummel, with $\mathrm{N}$-tosyl- $L$-arginine methyl ester (TAME) as substrate (14).

The concentration of polyethylene-glycol-4000 was measured according to Hyden (15); the dilution factor was calculated as described by Glasgow et al. (16). (Dilution factor = polyethylene-glycol concentration in the feeding fluid / polyethyleneglycol concentration in the feeding fluid - polyethylene-glycol in the aspirated fluid).

\section{Feces}

Total lipids of the faeces were determined gravimetrically after extraction using the 2-phase system chloroform, methanol, water $(1.0+0.9+1.0$ by vol. $)$,as published by Atkinson et al. (17) with slight modification.

\section{Statistics}

Since the values of enzymes, bile acids, and tyrosine were found to follow a log-normal distribution the statistical significance of differences between the 2 groups of subjects was calculated by Student's t-test after log transformation.

Tab. 1 a. Patients.

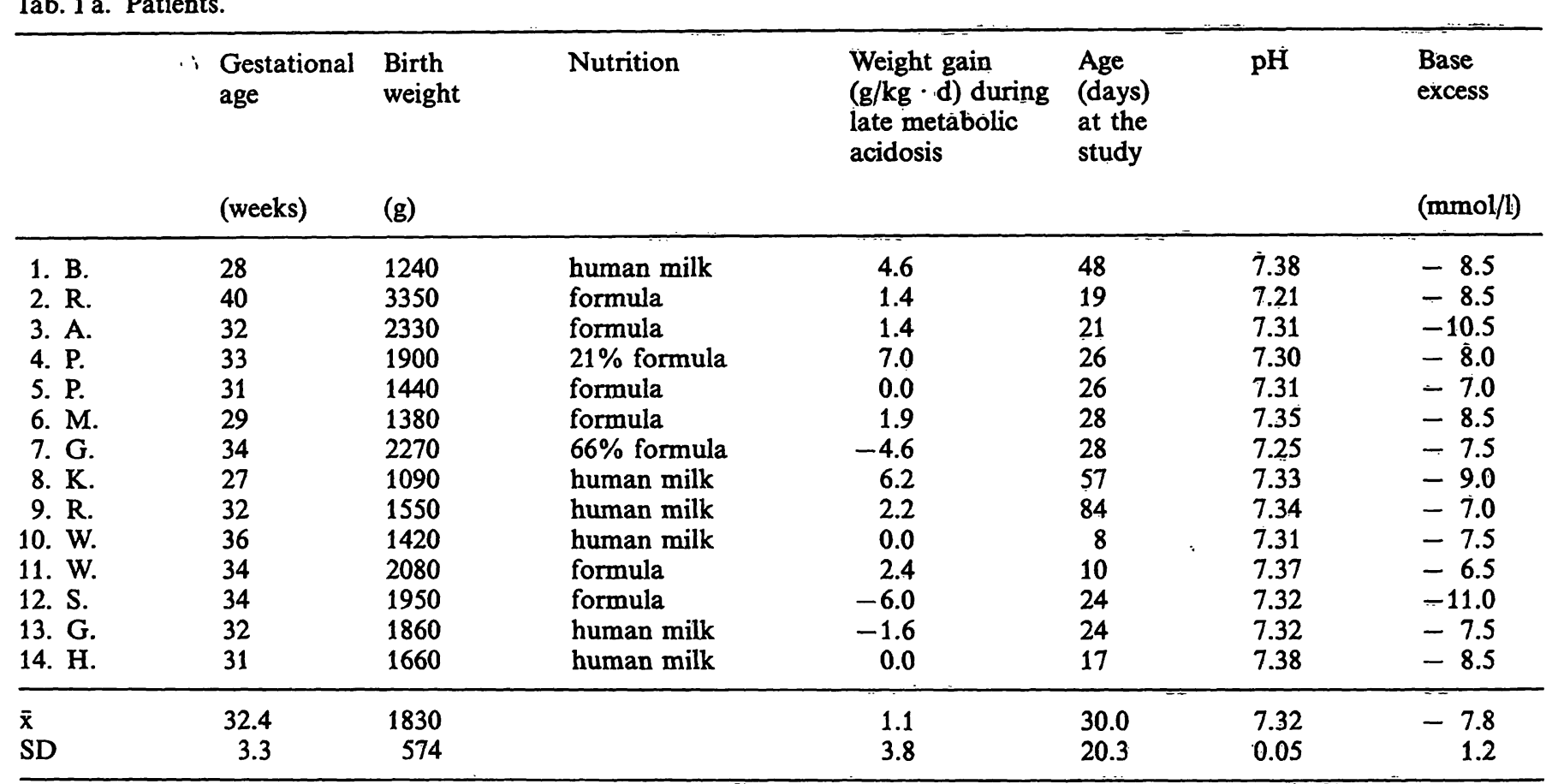

$\%$ represents percentage formula in mixture with human milk (\%)

Tab. 1.b. Controls.

\begin{tabular}{|c|c|c|c|c|c|c|c|}
\hline 1. $\mathbf{R}$. & 28 & 1420 & human milk & 11.8 & 62 & 7.37 & 0.5 \\
\hline 2. $\mathrm{S}$. & 34 & 1320 & human milk & 9.6 & 47 & 7.41 & 2.0 \\
\hline 3. $\mathrm{H}$. & 32 & 1620 & human milk & 9.7 & 39 & 7.35 & 0.0 \\
\hline 4. $\mathrm{P}$. & 36 & 2530 & human milk & 10.7 & 29 & 7.41 & -1.0 \\
\hline 5. V. & 34 & 1960 & human milk & 16.2 & 26 & 7.40 & -1.5 \\
\hline 6. $\mathrm{H}$. & 33 & 1900 & human milk & 11.7 & 14 & 7.41 & -2.0 \\
\hline 7. $\mathrm{H}$. & 31 & 1530 & human milk & 12.8 & 47 & 7.38 & -1.0 \\
\hline 8. J. & 32 & 1760 & human milk & 8.8 & 22 & 7.42 & 1.5 \\
\hline 9. W. & 32 & 2050 & human milk & 9.1 & 14 & 7.38 & -0.5 \\
\hline 10. P. & 33 & 2120 & human milk & 12.2 & 21 & 7.41 & 1.0 \\
\hline 11. B. & 33 & 2000 & human milk & 13.1 & 21 & 7.40 & $0 . \overline{5}$ \\
\hline 12. B. & 41 & 2910 & formula & 9.9 & 28 & 7.42 & -1.5 \\
\hline 13. F. & 27 & 1000 & human milk & 9.5 & 94 & 7.38 & -1.0 \\
\hline$\overline{\mathbf{x}}$ & 32.8 & 1855 & & 11.2 & 35 & 7.40 & -0.2 \\
\hline SD & 3.4 & 508 & & 2.1 & 23 & 0.03 & 1.3 \\
\hline
\end{tabular}




\section{Results}

As shown in table 1, the infants suffering from late metabolic acidosis showed a considerably decreased waight gain, a lower base excess and a lower $\mathrm{pH}$, compared with the controls.

Table 2 demonstrates the findings in the serum. The concentrations of bile acids and tyrosine in infants with late metabolic acidosis are significantly higher than those of the controls $(p<0.0005)$.

Table 3 gives the values for $\mathrm{pH}$, bile acids, and lipase in the gastric and duodenal juices of patients and controls.
Tube placement was found to be most precise when using lipase activity and bile acid concentration as indicators.

The concentration of bile acids and the activity of the lipase in duodenal juice was significantly lower in patients with late metabolic acidosis than in infants without late metabolic acidosis.

Figure 1 demonstrates the behaviour of bile acids, lipase, and trypsin in the duodenal juice following feeding. In figure $1 \mathrm{a}$ the measured concentrations or activities, respectively are plotted.

Figure $1 \mathrm{~b}$ shows the values after correction for dilution with gastric content.

Tab. 2. The concentrations of total bile acids and tyrosine in the blood serum of patients with late metabolic acidosis (a) and controls (b). All figures are given in $\mu \mathrm{mol} / \mathrm{l}$.

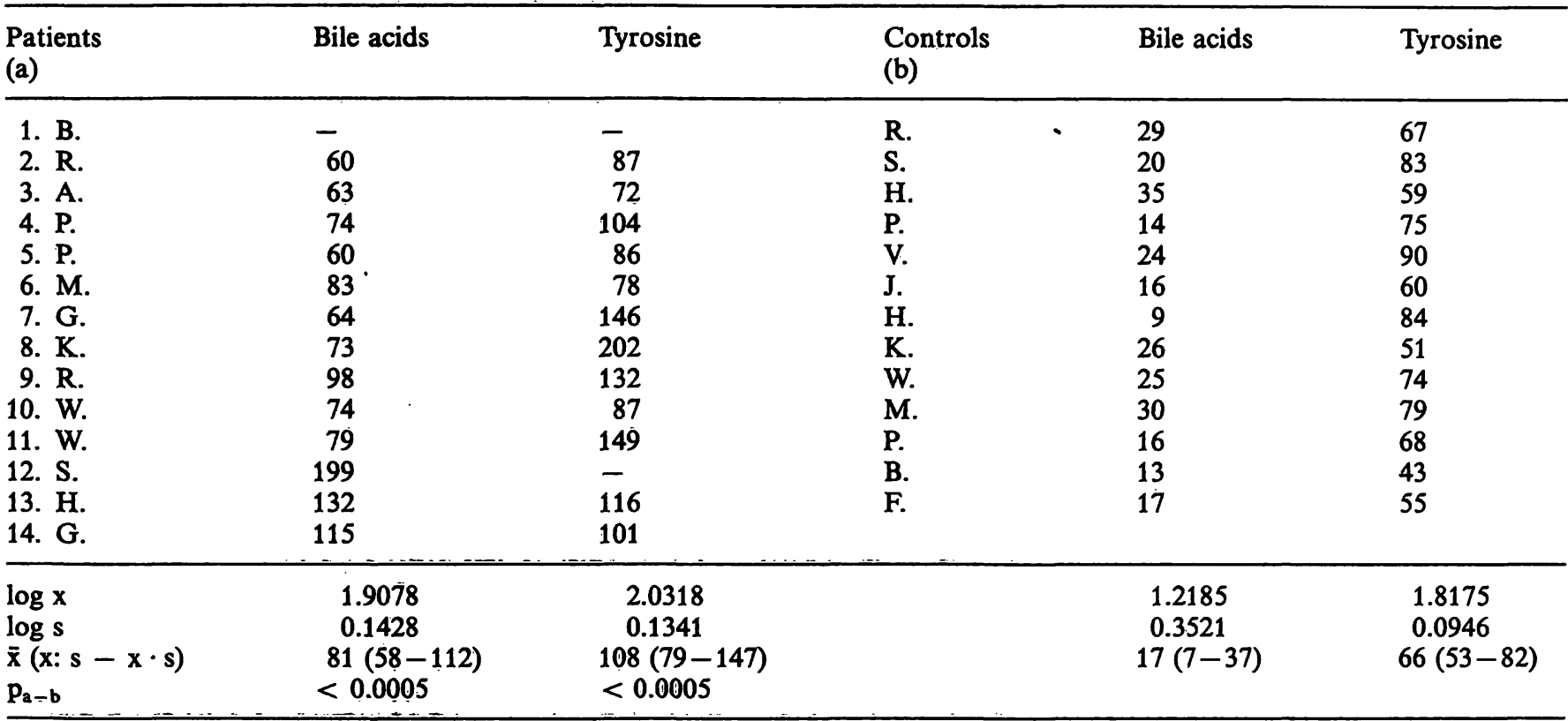

Tab. 3. Studies to decide the location of the tube. Statistical comparisons of $\mathrm{pH}$, bile acids (mmol/l) and lipase (kU/l) between patients (a) and controls (b) are given in horizontal level. The statistical comparisons between gastric and duodenal content of the groups are given in verticals. The numbers of patients and controls are given in brackets. The values represents (except the $\mathrm{pH})$ the delogarithmic means and the limit values in brackets $(\overline{\mathrm{x}}: \mathrm{s}-\overline{\overline{\mathrm{x}}} \cdot \mathrm{s})$.

\begin{tabular}{|c|c|c|c|c|c|c|c|}
\hline & \multicolumn{6}{|c|}{ Gastric content } & \multirow[t]{2}{*}{$\mathrm{p}$} \\
\hline & Patients & & & Controls & & & \\
\hline $\begin{array}{l}\text { pH } \\
\text { Bile acids } \\
\text { Lipase }\end{array}$ & $\begin{array}{l}4.5 \pm 1.5 \\
0.3 \\
1.0\end{array}$ & $\begin{array}{c}\dot{ } \\
(0.1-0.9) \\
(0.3-2.2)\end{array}$ & $\begin{array}{l}(9) \\
(11) \\
(11)\end{array}$ & $\begin{array}{l}5.3 \pm 1.6 \\
0.1 \\
0.1\end{array}$ & $\begin{array}{l}(0.1-0.3) \\
(0.0-0.4)\end{array}$ & $\begin{array}{l}(10) \\
(10) \\
(10)\end{array}$ & $\begin{array}{l}\text { n.s. } \\
\text { n.s. } \\
\text { n.s. }\end{array}$ \\
\hline \multirow[t]{2}{*}{$\begin{array}{l}\text { PpH } \\
\text { Pbile acids } \\
\text { Plipase }\end{array}$} & \multicolumn{3}{|l|}{$\begin{array}{l}<0.01 \\
<0.05 \\
<0.005\end{array}$} & \multicolumn{3}{|l|}{$\begin{array}{l}\text { n.s. } \\
<0.0005 \\
<0.0005\end{array}$} & \\
\hline & \multicolumn{6}{|c|}{ Duodenal content } & \\
\hline $\begin{array}{l}\text { pH } \\
\text { Bile acids } \\
\text { Lipase }\end{array}$ & $\begin{array}{l}6.2 \pm 0.2 \\
0.7 \\
8.3\end{array}$ & $\begin{array}{l}(0.4-1.5) \\
(1.2-20.3)\end{array}$ & $\begin{array}{l}(6) \\
(10) \\
(10)\end{array}$ & $\begin{array}{r}6.7 \pm 0.5 \\
4.9 \\
31.3\end{array}$ & $\begin{array}{l}(3.5-8.4) \\
(19.4-58.1)\end{array}$ & $\begin{array}{l}(7) \\
(9) \\
(9)\end{array}$ & $\begin{array}{l}\text { n.s. } \\
<0.001 \\
<0.005\end{array}$ \\
\hline
\end{tabular}




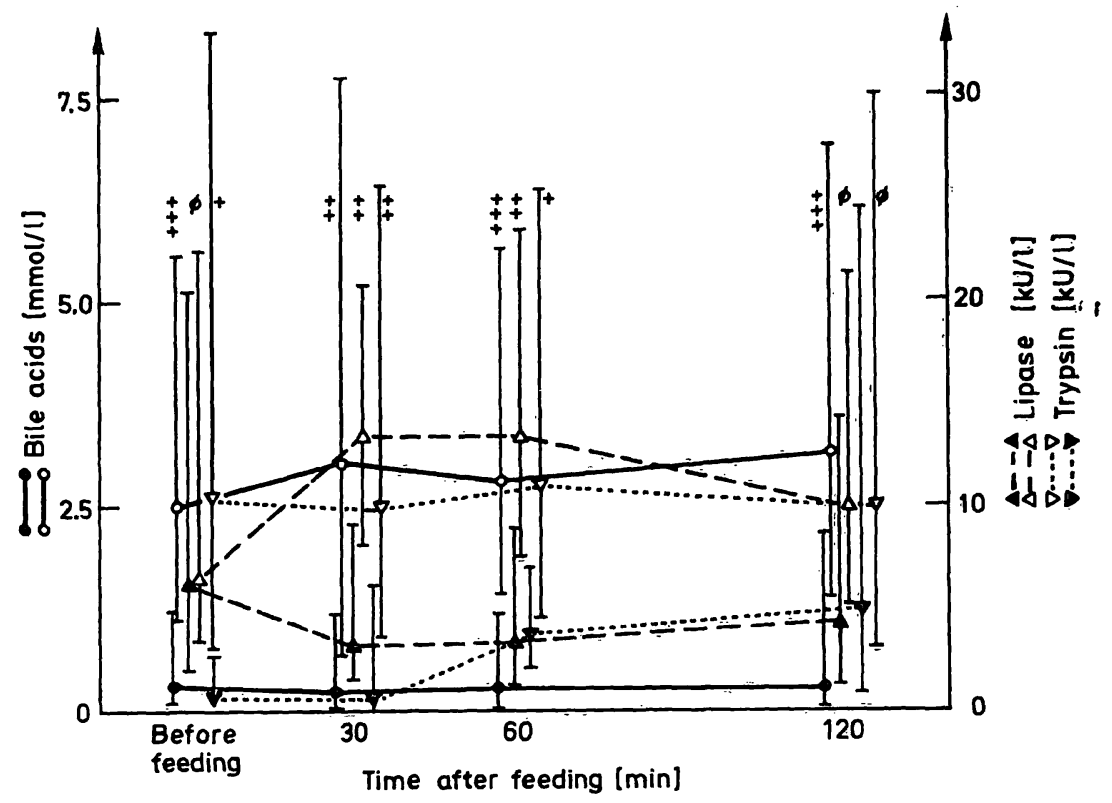

Fig. 1 a. Measured concentrations of bile acids $(0-0)$, and activities of lipase $(\Delta--\Delta)$ and trypsin $(\nabla \cdots \nabla)$ in the duodenal contents following feeding. Statistical significances of differences are indicated: $+p<0.001 ; \pm p<0.005 ;+p<0.01$; $\varnothing=$ not significant. Full symbols = patients; open symbols = controls.

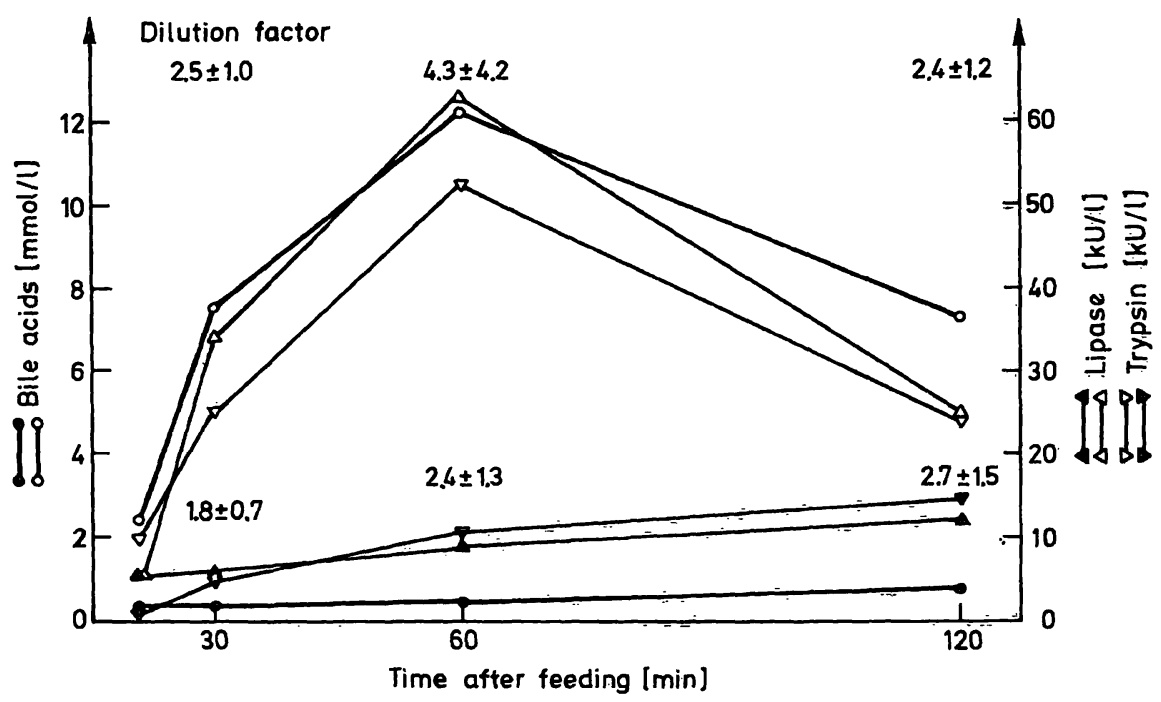

Fig. 1 b. The same parameters shown in fig. 1 a after correction for dilution with gastic content by multiplying with the given dilution factors (details in methods).

As depicted in figure $1 \mathrm{~b}$ a stimulation of bile and pancreatic secretion by feeding occurs only in the normal cases, whereas there is practically no rise in patients suffering from late metabolic acidosis.

Figure 2 represents the duodenal concentrations of total bile acids and the proportion of trihydroxy and dihydroxy bile acids during late metabolic acidosis, one week after late metabolic acidosis, in the controls, and in children 1-5 years of age. In addition to the decrease of total bile acid in duodenal juice during late metabolic acidosis, the concentrations of dihydroxy bile acids are very low, and in some cases not even detectable. Sometimes bile acid sulphates were found. Owing to their high $R_{r}$-values, $\Delta 5$-cholenic acid and lithocholic acid could not be quantified.

One week after late metabolic acidosis the duodenal parameters had risen to the values of control infants (bile acids: $p<0.001$; lipase $p<0.025$; trypsin; $\mathrm{p}<0.05$ ).

The quantity of daily excreted faeces was found to be higher in the cases with late metabolic acidosis $(11.6 \pm 1.5 \%$ of intake) than in the controls (6.6 $\pm 1.0 \%$ of intake). The total fat excretion was also higher in the patients with late metabolic acidosis (late metabolic acidosis: $39.1 \pm 6.6 \%$; controls 26.5 $\pm 5.2 \%$ of faecal weight, $p<.0 .001$ ). 


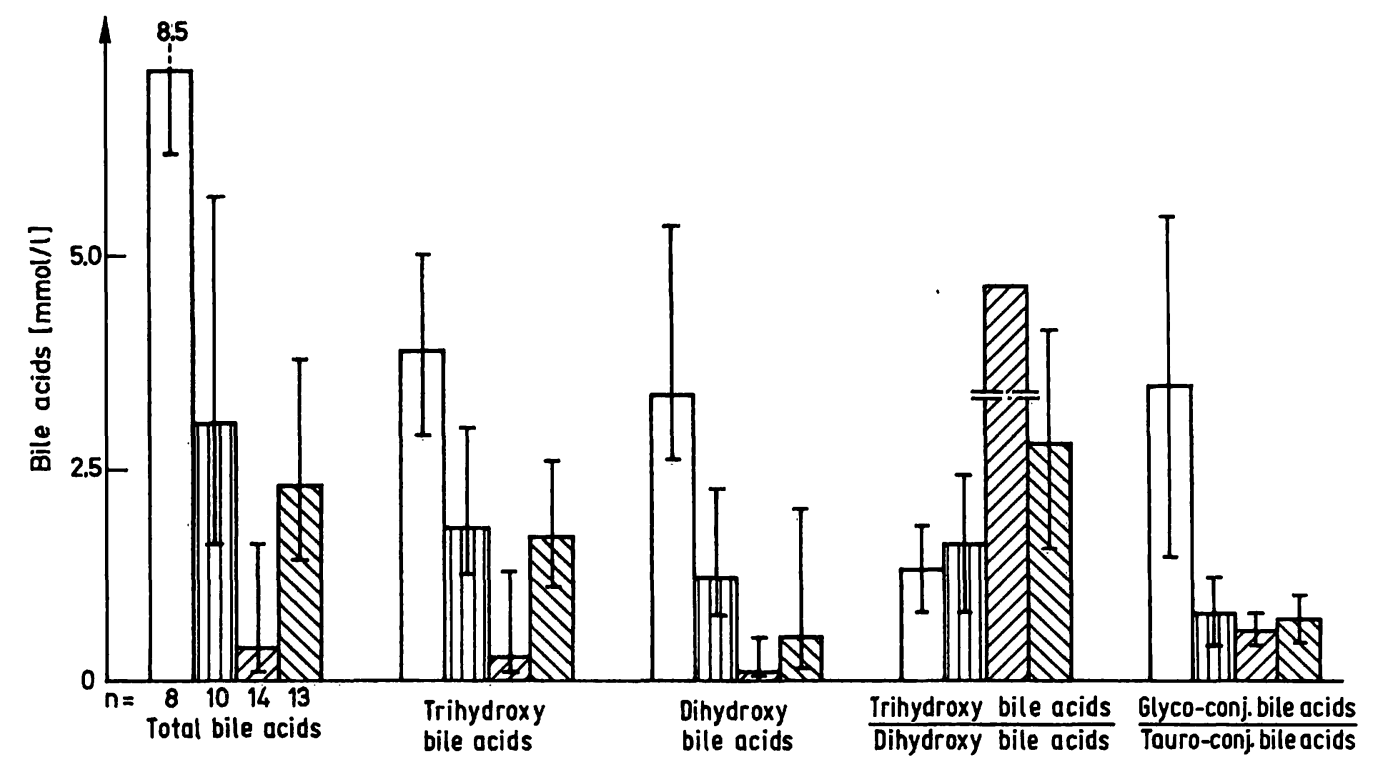

Fig. 2. The total bile acids, the trihydroxy and dihydroxy bile acids as well as the quotients of trihydroxy to dihydroxy bile acids in duodenal contents and glyco to tauro conjugates of bile acids of children 1 to 5 years of age ( $\square$ ), the patients one

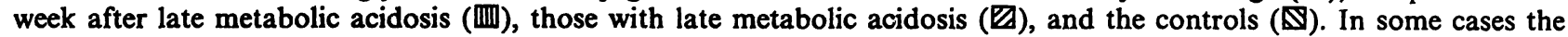
dihydroxy bile acids were not detectable. Therefore the high quotient is given without standard deviation.

\section{Discussion}

The increased bile acid concentration in the serum together with a decrease in the duodenal juice during late metabolic acidosis must be interpreted as a cholestatic situation. As a result of low bile acids and lipase in the duodenum the resorption of fat.is disturbed, and a high excretion of fat ensues. This explains the low energy retention factor of less than $50 \%$ in children with acidoses, described by Brooke (18).

Analogous to children with intrahepatic cholestasis, the infants with late metabolic acidosis studied here showed a parallel decline of both bile and pancreatic secretion $(19,20)$.

Of particular interest, but as yet not clarified, is the relation between the concentrations of bile acids and amino acids (tyrosine) (4). According to Bucuvalas et al. (6) the increased amino acid concentration in the serum might inhibit the uptake of bile acids into the liver.

\section{References}

1. Räihä, N. C. R., Heinonen, K., Rassin, D. K. \& Gaul, G. E. (1976) Pediatrics $57,659=674$.

2. Rassin, D. K., Gaul, D. E., Räihä, N. C. R. \& Heinonen, K. (1977) J. Pediatr. 90, 356-360.

3. Senger, H., Boehm, G., Pludra, R., Braun, W. \& Beyreiß, K. (1984) Dt. Gesundh.-Wesen 39, 935-938.

4. Senger, H., Boehm, G., Beyreiß, K., Braun, W. \& Räihä, N. (1986) Acta Paediatr. Scand. 75, 724-728.
The relation of acidosis and bile secretion is probably the best-known phenomenon in this field. In animal experiments, a decrease of bile secretion in the face of low $\mathrm{pH}$ and bicarbonate of the blood had been shown previously $(9,8)$. Our findings support these observations. Furthermore, recent results show a significant reduction of serum bile acid concentrations with concomitant elevation of duodenal bile acid concentrations after bicarbonate supplementation to oral feeding (21).

The decreased proportion of dihydroxy bile acid in the duodenal juice of our infants with late metabolic acidosis may have two explanations:

1. increased dependence on these bile acids with age (22) and

2. a particular reduction during formula feeding as shown by Watkins et al. (23).

5. Blitzer, B. L., Ratoosh, S. L. \& Donovan, C. B. (1983) Am. J. Physiol. 245, G399-G403.

6. Bucuvalas, J. C., Goodrich, A. L., Blitzer, B. L. \& Suchy, F. J. (1985) Pediatr. Res. 19, 1298-1304.

7. Pak, B. H., Hong, S. S., Pak, H. K. \& Hong, S. K. (1966) Am. J. Physiol. 210, 624-628.

8. Mathisen, O. \& Raeder, M. (1983) Eur. J. Clin. Invest. 13, $193-200$. 
9. Corbic, M., Munoz, C., Dumont, M., DeCouet, G. \& Erlinger, S. (1985) Hepatology 5. 594-599.

10. Boehm, G., Senger, H., Lorenz, I., Müller, D. M. \& BeyrciB, K. (1986) Acta Paediatr. Hung. 27, 107-113.

11. Senger, H., Pludra, R. \& Braun, W. (1987) Z. Med. Labor.Diagn. in press.

12. Waakles, T. P. \& Udenfried, S. (1957) J. Lab. Clin. Med. 50, 733-736.

13. Senger, H., Pludra, R. \& Braun, W. (1984) Z. Med. Labor.Diagn. 25, 52- 55 .

14. Hummel, B. C. W. (1959) Canad. J. Biochem. 37. $1393-1399$

15. Hyden, S. (1956) Ann. Roy Agric. Coll. Sweden 22 , $139-145$.

16. Glasgow, J. F. T., Dinsmorc, H., Molla, A. \& MacFarlane, T. (1980) Irish J. Med. Sci. 149, 346-356.
17. Atkinson, T., Fowler, V. R., Gaston, G. A. \& Lough, A. K. (1972) Analyst 97, 562-568.

18. Brooke, O. G. (1977) Arch. Dis. Childh. 52, 809.

19. Nießen, K. H. (1978) Monatsschr. Kinderheilk. I26, $343-345$.

20. BeyreiB, K., Scheerschmidt, G. Senger, H. (1984) Dt. Gesundh.-Wesen 39, 1730-1733.

21. Senger, H., Boehm, G., Friedrich, M., Müller, D. M., BeyreiB, K. \& Braun, W. (1987) Nahrung-Food 31, 919-922.

22. Encrantz, I. C. \& Sjövall, J. (1959) Clin. Chim. Acta 4, $793-799$.

23. Watkins, J. B., Järvenpää, A. L., Szezepanik van Leeuwen, P., Klein, P. D., Rassin, D. Kl., Gaul, G. \& Räihä, N. C. R. (1983) Gastroenterology 85, 793-800.

Dr. Hartmut Senger

Klinik für Kindermedizin

der Karl-Marx-Universität

Oststr. $21-25$

DDR-7050 Leipzig 